\title{
REFERÊNCIAS SOCIAIS DAS RELIGIÕES AFRO-BRASILEIRAS: SINCRETISMO, BRANQUEAMENTO, AFRICANIZACĀAOO
}

\author{
Reginaldo Prandi \\ Universidade de São Paulo - Brasil
}

Resumo: A história das religiões afro-brasileiras pode ser dividida em três momentos: 1) sincretização, durante a formação das modalidades tradicionais, 2) branqueamento, na formação da umbanda e 3) africanização, na transformação do candomblé em religião universal, isto $\hat{e}$, aberta a todos, sem barreiras de cor ou origem racial. O processo de africanização implica negação do sincretismo, adoção de aprendizado não oral e mudança ritual e doutrinária. O presente trabalho trata desses momentos e das condições sociais e culturais em que cada um veio a se constituir.

Palavras-chave: candomblé, religião, sincretismo, umbanda.

\begin{abstract}
The history of afro-brazilian religions can be divided in three moments: 1) syncretization, during the formation of the traditional modalities, 2) whitening, in the formation of umbanda and 3) africanization, in the tranformation of the candomble into universal religion, therefore if s opened to everybody, with no barriers of colour or racial origin. The process of africanization implies the denial of the syncretism, the adoption of a no-oral learning and the ritual and doctrinarian change. The following paper discusses these moments and the social and cultural conditions that each one was built in.
\end{abstract}

Keywords: candomblé, religion, syncretism, umbanda.

\section{Introducão}

A história das religiões afro-brasileiras pode ser dividida em três momentos: primeiro, o da sincretização com o catolicismo, durante a formação das modalidades tradicionais conhecidas como candomblé, xangô, tambor de mina e batuque; segundo, o do branqueamento, na formação da umbanda nos 
anos 20 e 30; terceiro, da africanização, na transformação do candomblé em religião universal, isto é, aberta a todos, sem barreiras de cor ou origem racial, africanização que implica negação do sincretismo, a partir dos anos 60.

Até os anos 1930, as religiões negras poderiam ser incluídas na categoria das religiões étnicas ou de preservação de patrimônios culturais dos antigos escravos negros e seus descendentes, enfim, religiões que mantinham vivas tradições de origem africana. Formaram-se em diferentes áreas do Brasil, com diferentes ritos e nomes locais derivados de tradições africanas diversas: candomblé na Bahia, xangô em Pernambuco e Alagoas, tambor de mina no Maranhão e Pará, batuque no Rio Grande do Sul, macumba no Rio de Janeiro. Na Bahia originou-se também o muito popular candomblé de caboclo e o menos conhecido candomblé de egum. O Nordeste foi berço também de outras modalidades religiosas mais próximas das religiões indígenas, mas que cedo ou tarde acabaram por incorporar muito das religiões afro-brasileiras ou as influenciar. Trata-se do catimbó, religião de espíritos aos quais se dá o nome de mestres e caboclos, que se incorporam no transe para aconselhar, receitar e curar. Esse tronco afro-ameríndio tem particularidades em diferentes lugares, sendo chamado de jurema, toré, pajelança, babaçuê, encantaria e cura.

No primeiro quartel deste século, no Rio de Janeiro e depois em São Paulo, constituiu-se a umbanda, que logo se disseminou por todo o País, abrindo, de certo modo, caminho para uma nova etapa de difusão do antigo candomblé. Reiteradamente identificada como sendo a religião brasileira por excelência, pois, formada no Brasil, resultante do encontro de tradições africanas, espíritas e católicas, ao contrário das religiões negras tradicionais, que se constituíram como religiões de grupos negros, a umbanda já surgiu como religião universal, isto é, dirigida a todos. Desde sua formação, a umbanda procurou legitimar-se pelo apagamento de feições herdadas do candomblé, sua matriz negra, especialmente traços referidos a modelos de comportamento e mentalidade que denotam a origem tribal e depois escrava.

Quando a umbanda já havia se propagado por todo o País, o candomblé, que se mantinha na Bahia e outras regiões em que se formara, também iniciou seu percurso na direção sul. Eram os anos 60 e já era outra a sociedade brasileira. A partir daí não foram necessários mais que trinta anos para que as religiões afro-brasileiras, antigas e novas, viessem a ocupar com destaque um lugar no cenário das religiões das grandes cidades. 
Nesses diferentes movimentos, numa sociedade em permanente processo de mudança, as religiões afro-brasileiras, ao se adaptarem a condições sociais historicamente diversificadas, experimentaram faces variadas, ora valorizando certos elementos de sua constituição, ora negando-os; ora se pondo ao lado do catolicismo, ora abandonando-o. ${ }^{1}$

\section{Sincretismo: a constituição da religião negra na sociedade branca}

Desde o seu início, as religiões afro-brasileiras formaram-se em sincretismo com o catolicismo e em grau menor com religiões indígenas. O culto católico aos santos, de um catolicismo popular de molde politeísta, ajustou-se como uma luva ao culto dos panteões africanos.

Desde sua formação em solo brasileiro, as religiões de origem negra têm sido tributárias do catolicismo. Embora o negro, escravo ou liberto, tenha sido capaz de manter no Brasil dos séculos XVIII e XIX, e até hoje, muito de suas tradições religiosas, é fato que sua religião enfrentou-se desde logo com uma séria contradição: na origem, as religiões dos bantos, iorubás e fons são religiões de culto aos ancestrais, que se fundam nas famílias e suas linhagens, mas as estruturas sociais e familiares às quais a religião dava sentido aqui nunca se reproduziram.

O tecido social do negro escravo nada tinha a ver com família, grupos e estratos sociais dos africanos nas suas origens. Assim, a religião negra só parcialmente pôde se reproduzir no Novo Mundo. A parte ritual da religião original mais importante para a vida cotidiana, constituída no culto aos antepassados familiares e da aldeia, pouco se refez, pois, na escravidão, a família se perdeu, a tribo se perdeu. Na África, era o ancestral do povoado (egungum) que cuidava da ordem do grupo, resolvendo os conflitos e punindo os transgressores que punham em risco o equilíbrio coletivo. Quando as estruturas sociais foram dissolvidas pela escravidão, os antepassados perderam seu lugar privilegiado no culto, sobrevivendo marginalmente no novo contexto social e ritual. As divindades mais diretamente ligadas às forças da natureza, mais

\footnotetext{
Para as diferentes modalidades religiosas afro-brasileiras, ver Bastide (1975, 1978); Carneiro (1936); Rodrigues (1935); Motta (1985, 1990); Pinto (1935); S. Ferretti (1986); M. Ferretti (1985, 1994); Eduardo (1948); Herskovits (1943); Corrêa (1992); Oro (1994); Prandi (1991a, 1996); Mazzoleni (1993); Santos (1992); Braga (1992); Segato (1995). Especificamente para a umbanda, ver Camargo (1961); Concone (1987); Ortiz (1978); Arcella (1980); Negrão (1996).
} 
diretamente envolvidas na manipulação mágica do mundo, mais presentes na construção da identidade da pessoa, os orixás, divindades de culto genérico, essas sim vieram a ocupar o centro da nova religião negra em território brasileiro. Pois que sentido poderia fazer o controle da vida social para o negro escravo? Fora de suas assembléias religiosas, era o catolicismo do senhor a única fonte possível de ligação com o mundo coletivo projetado para fora do trabalho escravo e da senzala.

Se a religião negra, ainda que em sua reconstrução fragmentada, era capaz de dotar o negro de uma identidade negra, africana, de origem, que recuperava ritualmente a família, a tribo e a cidade perdidas para sempre na diáspora, era por meio do catolicismo, contudo, que ele podia se encontrar e se mover no mundo real do dia-a-dia, na sociedade do branco dominador, que era o responsável pela garantia da existência do negro, ainda que em condições de privação e sofrimento, e que controlava sua vida completamente. Qualquer tentativa de superação da condição escrava, como realidade ou como herança histórica, implicava primeiro a necessária inclusão no mundo branco. E logo passava a significar o imperativo de ser, sentir-se e parecer brasileiro. Os negros não podiam ser brasileiros sem ser ao mesmo tempo católicos. Podiam preservar suas crenças no estrito limite dos grupos familiares - muitas vezes reproduzindo simbolicamente a família e os laços familiares mediante a congregação religiosa, daí a origem dos terreiros de candomblé e das famílias-de-santo —, mas a inserção no espaço maior exigia uma identidade nacional, por assim dizer, uma identidade que refletisse o conjunto geral da sociedade católica em expansão. ${ }^{2}$

O fim da escravidão, a formação da sociedade nacional, estruturada em classes, o extravasamento das populações pelas amplitudes geográficas, com a criação de oportunidades sociais as mais diferentes, tudo isso só fez reforçar a importância do catolicismo para as populações negras. O próprio catolicismo, como cultura de inclusão, hegemônica, não fez oposições, que não pudessem ser vencidas, ao fato de o negro manter uma dupla ligação religiosa.

Assim, as religiões afro-brasileiras sempre foram devedoras e dependentes do catolicismo, ideológica e ritualmente. Só muito recentemente as religiões de origem negra começaram a se desligar do catolicismo, já numa época

2 Para outras interpretações e aspectos do sincrestismo católico nas religiões afro-brasileiras, ver Valente (1977); S. Ferretti (1995); Sanchis (1995). 
em que a sociedade brasileira não precisa mais do catolicismo como a grande e única fonte de transcendência que possa legitimá-la e fornecer-lhe os controles valorativos da vida social. Mas isso é um projeto de mudança nos referenciais de identidade que mal começou e que exige, antes, outras experiências de situar-se no mundo com mais liberdade e direitos de pertença. ${ }^{3}$

Desobrigadas, desde o nascimento, das questões referentes à administração da justiça, que pressupõe princípios universalistas e pactos coletivos acima dos desejos individuais, posto que isso era domínio exclusivo da religião geral da sociedade geral, o catolicismo; desinteressadas de conteúdos formadores da pessoa para o mundo profano, porque o modelo aqui é branco; alimentando o culto de deuses que se exteriorizam e se expressam especialmente por intermédio da forma, não é sem razão que as religiões afro-brasileiras desenvolveram um enorme senso ritual presidido por inigualável senso estético, capaz de transbordar os limites do sagrado para se impregnar nas expressões mais profanas que modelam a identidade nacional

Em virtude do rico patrimônio cultural que lograram conservar, as religiões negras, especialmente a partir dos anos 60, reencontraram-se com a sociedade brasileira no campo das artes, fornecendo à cultura popular muito de seu repertório, que é convertido em arte profana para o consumo das massas, ganhando, em troca, reconhecimento e prestígio. Mas antes disso houve um longo percurso em que a religião dos orixás foi deixando de lado seus aspectos africanos para incorporar uma face mais européia, mais branca.

\section{Branqueamento: a formação da umbanda para a sociedade branca}

No final do século XIX, originário da França, chegou ao Brasil o espiritismo de Alan Kardec, religião que fundia certa concepção kármica do mundo de inspiração hindu com preceitos cristãos e um certo racionalismo do século XIX. O espiritismo kardecista logo se firmou no Brasil, sendo desde o começo uma religião de classe média, embora também freqüentada por pobres e negros. No Rio de Janeiro, os negros que aderiam ao espiritismo traziam para

\footnotetext{
Trata-se do movimento de africanização do candomblé, que procura desfazer o sincretismo com o catolicismo e recuperar elementos rituais perdidos na diáspora negro-africana, além de reaprender a língua iorubá. Entre suas importantes lideranças destacam-se Mãe Stella Azevedo do Axê Opô Afonjá da Bahia e Mãe Sandra Medeiros Epega do Ilê Leuiwyato de São Paulo.
} 
os centros da nova religião muito de suas tradições do candomblé, o que provocava muitas vezes conflitos com o modelo “europeu” da religião de Kardec.

Assim, o primeiro centro de umbanda teria sido fundado no Estado do Rio de Janeiro, em meados dos anos 1920, como dissidência de um kardecismo que rejeitava a presença de guias negros e caboclos, considerados pelos espíritas mais ortodoxos como espíritos inferiores. Logo, seguiu-se a formação de muitos outros centros desse espiritismo então chamado de espiritismo de umbanda. Do Rio de Janeiro, a umbanda instalou-se e se expandiu em São Paulo rapidamente, depois pelo País inteiro. Em 1941, realizou-se no Rio de Janeiro o Primeiro Congresso de Umbanda, congresso ao qual compareceram também umbandistas de São Paulo.

Com a umbanda iniciou-se vigoroso processo de valorização de elementos nacionais, como o caboclo e o preto velho, que são espíritos de índios e escravos. A umbanda nascente retrabalhou os elementos religiosos incorporados à cultura brasileira por um estamento negro que se diluía e se misturava aos brancos pobres na constituição das novas classes sociais numa cidade, então a capital federal, que era branca, mesmo quando proletária, era culturalmente européia, valorizava a organização burocrática da qual vivia então boa parte da população residente, premiava o conhecimento pelo aprendizado escolar em detrimento da tradição oral, e já conhecia o kardecismo como religião.

Tratava-se de "limpar" a religião nascente de seus elementos mais comprometidos com a tradição iniciática secreta e sacrificial, tomando por modelo o kardecismo, que expressava ideais e valores da nova sociedade capitalista e republicana, ali na sua capital. Os passos decisivos foram a adoção da língua vernácula, a simplificação da iniciação, a eliminação quase total do sacrifício de sangue. Manteve-se o rito cantado e dançado dos candomblés, bem como um panteão simplificado de orixás, já porém havia muitos anos sincretizados com santos católicos, reproduzindo-se um calendário litúrgico que segue o da Igreja Católica. Entretanto, o centro do culto no seu dia-a-dia estará ocupado pelos guias, caboclos, pretos velhos e mesmo os “maléficos” e interesseiros exus masculinos e femininos, as pombagiras, já cultuados em antigos candomblés baianos e fluminenses (Prandi, 1996a, capítulo 4).

A umbanda rompeu de certo modo com a concepção kardecista de mundo, que ensina que esta é mais uma terra de sofrimentos onde devemos ajustar contas por atos de nossas vidas anteriores. Não para a umbanda, que herdou do candomblé a idéia de a experiência neste mundo implicar a obrigação de 
gozá-lo, a idéia de a realização do homem se expressar por meio da conquista da felicidade terrena, questionando assim a noção kardecista da evolução kármica (o que somos hoje depende de como agimos numa vida passada), que enfatiza a culpa e o conformismo. Com a prática da oferenda ritual, que propicia os deuses a nosso favor, a umbanda reafirma a possibilidade de mudança da ordem, de intervenção no mundo de acordo com interesses e vontades individuais. É necessário que cada um procure a sua realização plena, mesmo porque o mundo com o qual nos deparamos é um mundo que valoriza o individualismo, a criatividade, a expansão da capacidade de imaginação, a importância de "subir na vida". Este pormenor é essencial

Por essa forma de ver o mundo, a umbanda situa-se como uma religião que incentiva a mobilidade social. Mais importante do que isso, entretanto, é o fato de que essa mobilidade está aberta a todos, sem nenhuma exceção: pobres de todas as origens, brancos, pardos, negros, árabes... O status social não está mais impresso na origem familiar, muito menos na origem racial. Trata-se agora, para cada um, de mudar o mundo a seu favor. E essa religião é capaz de oferecer um instrumento a mais para isso: a manipulação do mundo pela via ritual. Com a umbanda, as cidades grandes do Sudeste, depois todas as outras, conheceram o despacho a Exu, a oferenda depositada nas encruzilhadas.

Assim, até o final dos anos 50, a história das religiões afro-brasileiras é uma história de apagamento de características de origem africana e sistemático ajustamento à cultura nacional de preponderância européia, que é branca. Mas, no processo de branqueamento, muitas práticas rituais e concepções religiosas negras impuseram-se na sociedade branca.

\section{Africanização: a expansão do candomblé e o retorno às origens negras}

Por volta de 1950, a umbanda já tinha se consolidado como religião aberta a todos, não importando as distinções de raça, origem social, étnica e geográfica. Por ter a umbanda desenvolvido sua própria visão de mundo, bricolagem européia-africana-indígena, símbolo das próprias origens brasileiras, ela pôde apresentar-se como fonte de transcendência capaz de substituir o velho catolicismo ou então juntar-se a ele como veículo de renovação do sentido religioso da vida. Depois de ver consolidados os seus mais centrais aspectos, ainda no Rio de Janeiro e São Paulo, a umbanda espalhou-se por todo o País, 
podendo ser também agora encontrada vicejando na Argentina, no Uruguai e em outros países latino-americanos, além de Portugal. ${ }^{4}$

Mas as religiões afro-brasileiras como estavam constituídas até essa época podem ser consideradas ainda como religiões de negros. Ainda eram até mesmo controladas pela polícia e pela saúde pública. A própria umbanda, que fez um enorme esforço para se apresentar à sociedade branca como religião branca (Ortiz, 1978), ainda era olhada com muito preconceito. Liderada por pessoas de extração social de classe média baixa, em que se destacaram oficiais militares e policiais, pequenos comerciantes, donas-de-casa, a umbanda era chamada de "baixo espiritismo" e vista com muitas reservas, não tendo conseguido atrair para suas fileiras intelectuais, artistas e jornalistas de expressão, como acontecera com o espiritismo kardecista. No caso do candomblé, este fizera-se cercar desde seus primórdios de pessoas influentes na sociedade: profissionais intelectuais que nutriam pela religião dos negros simpatia e admiração e que mantinham com os terreiros de candomblé e seus dirigentes laços afetivos e de solidariedade. Os candomblés criaram para essas pessoas um cargo hierárquico que representava uma espécie de pai protetor, o ogã, a quem cabia estabelecer uma espécie de ponte entre o terreiro e o mundo branco, protegendo o grupo de culto da perseguição policial, resolvendo problemas burocráticos e políticos, ajudando financeiramente no provimento dos ritos. Intelectuais e artistas de grande prestígio receberam (e continuam recebendo) tal honraria.

Durante os anos 60, algo surpreendente começou a acontecer. Com a larga migração do Nordeste em busca das grandes cidades industrializadas no Sudeste, o candomblé começou a penetrar o bem estabelecido território da umbanda, e velhos umbandistas começaram a iniciar-se no candomblé, muitos deles abandonando os ritos da umbanda para se estabelecer como pais e mães-de-santo das modalidades mais tradicionais de culto aos orixás. Nesse movimento, a umbanda foi remetida de novo ao candomblé, sua velha e "verdadeira" raiz original, considerada pelos novos seguidores como sendo mais misteriosa, mais forte, mais poderosa que sua moderna e embranquecida descendente.

4 Sobre a presença das religiões afro-brasileiras em países do Cone Sul, ver Oro (1993); Frigerio e Carozzi (1993); Pi Hugarte (1993); Prandi (1991b); na Venezuela, Pollak-Eltz (1993); em Portugal, Pordeus Jr. (1996). 
Os anos durante os quais o candomblé instalou-se em São Paulo, entre os meados dos 60 e os primeiros anos dos 70 , e que estamos habituados a chamar simplesmente de “os anos 60", marcam um período de vital efervescência no plano da cultura e das mentalidades; profundas foram as mudanças em relação aos modos de vida e aos códigos intelectuais, quando a racionalidade foi posta sob suspeição, assim como a crença completa no conhecimento universitário e seus modelos fechados de explicação do mundo. Antevia-se o que viria mais tarde dar no chamado pós-moderno. O movimento de contestação dos anos 60, que se iniciou na Europa e nos Estados Unidos, logo chegou ao Brasil, sobremaneira ao Sudeste, às grandes cidades, ganhando adeptos entre intelectuais e estudantes secundaristas e universitários.

São os anos da contracultura, da recuperação do exótico, do diferente, do original. A juventude ocidental ilustrada rebelou-se, tomou gosto pelas civilizações orientais, seus mistérios transcendentais e ocultistas (lembremo-nos dos Beatles e da peregrinação da juventude americana e européia em busca dos gurus do Himalaia). Valorizou-se a cultura do outro. No Brasil, a cultura indígena, e a Antropologia redimensionou a etnografia para fazer política indigenista. E também a cultura do negro. A sociedade saía em busca de suas raízes. Era preciso voltar à Bahia e - por que não? - acampar em Arembepe. Abrir as portas da percepção, ir em busca do prazer, da expansão da sensibilidade, de gratificações imediatas para o corpo e para a mente.

Nesse período da história brasileira, as velhas tradições religiosas de origem africana até então preservadas na Bahia e outros pontos do País encontraram excelentes condições econômicas para se reproduzirem e se multiplicarem mais ao sul; o alto custo financeiro dos ritos deixou de ser um constrangimento que as pudesse conter. Ao mesmo tempo, no âmbito desse movimento de classe média que buscava por aquilo que poderia ser tomado como as raízes originais da cultura brasileira, muitos intelectuais, poetas, estudantes, escritores e artistas de renome foram bater à porta das velhas casas de candomblé da Bahia. Ir a Salvador para se ter o destino lido nos búzios pelas mães-de-santo tornou-se um must para muitos, uma necessidade que preenchia o vazio aberto por um estilo de vida moderno e secularizado, tão enfaticamente constituindo mudanças sociais que demarcavam o jeito de viver nas cidades industrializadas do Sudeste, estilo de vida já - quem sabe? - eivado de tantas desilusões.

O candomblé encontrou condições sociais, econômicas e culturais muito favoráveis para o seu renascimento num novo território, em que a presença de 
instituições de origem negra até então pouco contavam. Nos novos terreiros de orixás que foram se criando então, entretanto, podiam ser encontrados pobres de todas as origens étnicas e raciais. Eles se interessaram pelo candomblé e os terreiros cresceram às centenas. O candomblé, a partir do Sudeste, foi transformando-se também em religião universal, isto é, religião para todos.

Nesse período de intensa efervescência cultural e política - basta lembrar o golpe militar de 1964 e os longos anos de repressão ditatorial e de resistência dos movimentos de estudantes e trabalhadores -, os movimentos da juventude de esquerda tiveram intensa atuação em áreas como teatro e música, ao mesmo tempo que se desenvolvia uma concepção de sociedade que implicava a valorização do pobre, do negro, do explorado e do marginalizado, em que se incluía a favela e o morro cariocas, que passam a ser cantados pelos compositores e intérpretes da música popular de elite como pólos de luta contra a injustiça social.

O inconformismo e o desprezo pela cultura racional concentravam-se nas classes médias ilustradas. Logo configurou-se um movimento cultural definido ao mesmo tempo como sendo de protesto, de esquerda e de renovação, o qual se mostra através da mídia, que já era eletrônica, trazendo para dentro dos lares um volume de informações antes não conhecido e incentivando o surgimento de novos gostos. O País vivia a euforia política e cultural que precedeu o golpe de 1964, sucedida pela agitação dos anos de resistência à ditadura militar que vieram. A intelectualidade brasileira de maior legitimidade nos anos 60 participou ativamente de um projeto cultural de recuperação de origens, que remetia muito diretamente à Bahia.

Nesse contexto, econômico, social e cultural, o candomblé chegou e se instalou em São Paulo e em outras regiões do país nas quais era nada ou pouco conhecido. Já não como religião de negros; mas religião voltada para todos, independentemente de raça, embora nas regiões de origem continue sendo majoritariamente de negros. ${ }^{5}$

A religião dos orixás conserva sua imagem de culto de mistérios e segredos, o que implica a idéia de perigo e risco no imaginário popular, fato que realimenta o preconceito, mas sem dúvida terá caminhado no processo de

\footnotetext{
5 Para o conjunto da população brasileira adulta, no ano de 1994, os seguidores das religiões afro-brasileiras (todas as modalidades) têm a seguinte distribuição: 51\% são brancos; 29\%, pardos e 18\%, pretos. A umbanda separadamente tem $57 \%$ de seguidores brancos, $27 \%$ de pardos e $15 \%$ de pretos. O candomblé tem $40 \%$ de brancos, 33\% de pardos e 24\% de pretos (Prandi, 1996a, capítulo 2).
} 
legitimação: já não se esconde da polícia nem se limita mais a parcelas fechadas da população. A divulgação profana da religião pelas artes, especialmente a música popular, que atinge as massas pelo rádio e televisão, terá sem dúvida contribuído para reduzir a marginalidade da religião dos deuses africanos.

Como religião que agora é de todos, o candomblé enfatiza a idéia de que a competição na sociedade é bem mais aguda do que se podia pensar, que é preciso chegar a níveis de conhecimento muito mais densos e cifrados, que o poder religioso tem amplas possibilidades de se fazer aumentar. Ensina que não há nada a esconder ou reprimir, com relação a si mesmo e com relação aos demais. Pois neste mundo podemos ser o que somos, o que gostaríamos de ser e o que os outros gostariam que fôssemos. A um só tempo.

Como agência de serviços mágicos, oferece ao não-devoto a possibilidade de encontrar solução para problema não resolvido por outros meios, sem maiores envolvimentos com a religião (Pierucci; Prandi, 1996, capítulo 11). Aos olhos do cliente, a densa sacralidade do candomblé pode passar despercebida. Como os ritos iniciáticos do candomblé são realizados longe dos olhos do público, o não-iniciado só vê o rito público, que é a festa, com música, canto, dança, comida e muita cor. O candomblé assim é muito confundido com sua forma estética, a qual se reproduz no teatro, na escola de samba, na novela da televisão - os orixás ao alcance da mão como produto de consumo legítimo.

Parcela importante da legitimidade social de elementos dessa cultura negra, ou de origem africana, cujo celeiro mais importante é a Bahia, essa legitimação da "raiz", terá sido gestada pela nova estética da classe média intelectualizada do Rio e de São Paulo dos anos 60 e 70, que adotou os artistas e intelectuais baianos, inclusive, e propagou-se pela mídia eletrônica, chegou a todas as classes sociais; com especialmente publicização na música popular (Prandi, 1997a). Chegou também aos pobres, ainda que não tenham vivido o desejo de retorno e rebeldia que nos anos 60 rumou para Salvador, atracou no Porto da-Barra, subiu a ladeira do Gantois no bairro da Federação, encontrou o caminho de São Gonçalo do Retiro e se embrenhou pelas sendas do Matatu de Brotas, em busca das veneráveis mães-de-santo e seus feitiços. Desejo que se alastrou também entre umbandistas, que com esforço buscavam até então apagar justamente essa origem não-branca de sua religião, essa Bahia, essa África.

Começava o que chamei de processo de africanização do candomblé (Prandi, 1991a), em que o retomo deliberado à tradição significa o reaprendizado da língua, dos ritos e mitos que foram deturpados e perdidos na 
adversidade da diáspora; voltar à África não para ser africano nem para ser negro, mas para recuperar um patrimônio cuja presença no Brasil é agora motivo de orgulho, sabedoria e reconhecimento público, e assim ser o detentor de uma cultura que já é ao mesmo tempo negra e brasileira, porque o Brasil já se reconhece no orixá.

No imaginário desse crente, crente que é pobre, o orixá “original”, cantado e cortejado por aquele que é mais rico, mais escolarizado, famoso e mais bem-sucedido na vida, esse orixá cultuado à moda "antiga”, à moda dos candomblés, vai se revelando mais forte, mais rico, mais "autêntico", mais poderoso.

Ao longo do processo de mudanças socioculturais aqui esboçado, o culto aos orixás primeiro misturou-se ao culto dos santos católicos para ser brasileiro - forjou-se o sincretismo; depois apagou elementos negros para ser universal e se inserir na sociedade geral - gestou-se a umbanda; finalmente retornou às origens negras para fazer parte da própria identidade do País - o candomblé foi se transformando em religião para todos, iniciando um processo de africanização e dessincretização para recuperar sua autonomia em relação ao catolicismo.

O sacerdócio no candomblé também é um meio de mobilidade social ascendente (como o clero católico foi para muitas famílias pobres com projetos de ascensão para seus filhos, como toda liderança religiosa, qualquer que seja, o é), e aqueles que começam a ser bem-sucedidos socialmente (o que implica clientela) tendem a se envolver na busca de prestígio simbólico, que, como acontece nas religiões em geral e no candomblé em particular, pressupõe uma pureza original, que vem do passado (a África através da Bahia) ou do presente (a África ela mesma, a de hoje). No processo de legitimação que foi se firmando em São Paulo desde o final dos anos 70, a maioria dos sacerdotes que se deixam envolver nesse processo é forçada a peregrinar à África, dar obrigações e tomar cargos nos templos da Nigéria e do Benin, repetindo a saga de Martiniano do Bonfim, da Bahia, e de Adão, do Recife, entre outros “grandes” dos anos 30.

Isso é africanizar. Mas africanizar não significa nem ser negro nem desejar sê-lo e muito menos viver como os africanos. Lembremo-nos da grande parcela de seguidores do candomblé formada por adeptos brancos.

Africanizar significa também a intelectualização, o acesso a uma literatura sagrada contendo os poemas oraculares de Ifá, a reorganização do culto 
conforme modelos ou com elementos trazidos da África contemporânea (processo em que o culto dos caboclos é talvez o ponto mais vulnerável, mais conflituoso); implica o aparecimento do sacerdote na sociedade metropolitana como alguém capaz de superar uma identidade com o baiano pobre, ignorante e preconceituosamente discriminado.

Cada um, a partir da África e fora do circuito dominante do candomblé baiano, reconstrói seu terreiro selecionando os aspectos que lhe pareçam mais convenientes ou interessantes. Nesse sentido, africanização também é bricolagem, também é invenção de tradições. Não é a volta ao original primitivo, mas a ampliação do espectro de possibilidades religiosas para uma sociedade moderna, em que a religião é também serviço e, como serviço, se apresenta no mercado religioso, de múltiplas ofertas, como dotada de originalidade, competência e eficiência.

A religião tradicional que migrou e que se refez na cidade moderna vai assim se mostrando como imagem caricatural da sociedade atual, que é a sociedade da diferença e da multiplicidade. Nessa sociedade secularizada, em que não há mais lugar para a religião única e hegemônica, capaz, como no passado recente, de ditar regras para a sociedade como um todo, nessa sociedade que não precisa mais de deuses, que seguem cultuados em vista agora das necessidades dos indivíduos, nessa sociedade o candomblé vai se expandindo como uma das infindáveis religiões da metrópole contemporânea.

Conforme disse em outra oportunidade, nessa nova sociedade, em que muitas referências fundamentais vão se alterando e alternando, também muda a religião. Ela passa a ser sem fronteira e sem território, sem ser contudo universal, no sentido de religião que se pretende única, como o catolicismo, o protestantismo clássico e o islamismo (Prandi, 1996b). A religião agora depende das forças de oferta e procura, devendo adaptar-se a novas situações e novas demandas. Reage às suas concorrentes lançando mão da propaganda e dos meios eletrônicos de comunicação, simplificando sua linguagem em função de um limitado número de “produtos” religiosos cuja propalada eficácia é o atrativo dos neodevotos que arrebata em massa. Sobretudo especializa-se, abrindo mão de sua velha natureza de cultura e instituição totalizadora, vocacionada para dar conta de todas as coisas. A religião se esparrama e se fragmenta, perde sua origem, que deve ser refeita a cada nova demanda, ganha espaços e mercado. É agora uma das infindáveis religiões do mundo, onde tudo se sabe e onde tudo se consome, se vende e se compra. Para ser um dia, 
quem sabe?, a religião do mercado sem fronteiras. Aí se pode observar a presença da religião dos orixás, aos quais vêm se juntar outros deuses africanos, mas menos conhecidos dos brasileiros mais ao sul: os voduns, numa trama de refazimento de tradições e novas possibilidades de culto como nunca se viu, e como é próprio da sociedade secularizada e pluralista (Prandi, 1997b).

E essas novas religiões, novas apesar de sua origem antiga, não dependem mais do catolicismo como mecanismo de identidade para seus devotos. Não é mais preciso ser católico para ser brasileiro; pode-se ter qualquer religião, ou nenhuma. O sincretismo não faz mais sentido e para muitos dos adeptos do candomblé, sobretudo sua liderança mais esclarecida (em todas as partes do Brasil), retirar dessa religião afro-brasileira os elementos católicos faz parte desse retorno à origem, dessa volta à África, que é uma retomada de símbolos religiosos e não o desejo de retorno às condições de vida do negro, do escravo, do antigo.

Ao negar o sincretismo, deixando para trás a religião da Igreja, seus ritos e santos, o novo candomblé se põe em pé de igualdade com o catolicismo, deixa de ser religião subalterna, já não se vê a si mesmo como a religião do escravo.

\section{Referências}

ARCELLA, L. Rio macumba. Roma: Bulzoni, 1980.

BASTIDE, R. As religiões africanas no Brasil. São Paulo: Pioneira, 1975.

BASTIDE, R. O candomblé da Bahia: rito nagô. São Paulo: Nacional, 1978.

BRAGA, J. Ancestralidade afro-brasileira: o culto de babá egum. Salvador: CEAO/UFBa: Ianamá, 1992.

CAMARGO, C. P. F. de. Kardecismo e umbanda. São Paulo: Pioneira, 1961.

CARNEIRO, E. Religiões negras. Rio de Janeiro: Civilização Brasileira, 1936.

CONCONE, M. H. V. B. Umbanda, uma religião brasileira. São Paulo: Faculdade de Filosofia, Letras e Ciências Humanas da USP, 1987. 
CORRÊA, N. F. O batuque do Rio Grande do Sul: antropologia de uma religião afro-rio-grandense. Porto Alegre: Editora da Universidade/UFRGS, 1992.

EDUARDO, O. da C. The negro in Northern Brazil. Seattle: University of Washington Press, 1948.

FERRETTI, M. M. R. Mina, uma religião de origem africana. São Luís: SIOGE, 1985.

FERRETTI, M. M. R. Terra de caboclo. São Luís: SECMA, 1994.

FERRETTI, S. F. Querebentan de Zomadonu: etnografia da Casa das Minas. São Luís: Editora da Universidade Federal do Maranhão, 1986.

FERRETTI, S. F. Repensando o sincretismo: estudo sobre a Casa das Minas. São Paulo: Edusp; São Luís: FAPEMA, 1995.

FRIGERIO, A.; CAROZZI, M. J. Las religiones afro-brasileñas en Argentina. Cadernos de Antropologia, Porto Alegre: UFRGS, n. 10, 1993.

HERSKOVITS, M. J. The Southernmost outpost of the New World Africanisms. American Anthropologist, v. 45, n. 4, p. 495-590, 1943.

MAZZOLENI, G. Maghi e messia del Brasile. Roma: Bulzoni, 1993.

MOTTA, R. (Org.). Os afro-brasileiros. In: ANAIS DO III Congresso AfroBrasileiro. Recife: Massangana, 1985.

MOTTA, R. Meat and feast: the Xango religion of Recife, Brazil. Ann Arbor: UMI Dissertation Information Service, 1990.

NEGRÃO, L. N. Entre a cruz e a encruzilhada. São Paulo: Edusp, 1996.

ORO, A. P. As religiões afro-brasileiras: religiões de exportação. Cadernos de Antropologia, Porto Alegre: UFRGS, n. 10, 1993.

ORO, A. P. (Org.). As religiões afro-brasileiras do Rio Grande do Sul. Porto Alegre: Editora da Universidade/UFRGS, 1994. 
ORTIZ, R. A morte branca do feiticeiro negro. Petrópolis: Vozes, 1978.

PI HUGARTE, R. Las religiones afro-brasileñas en el Uruguay. Cadernos de Antropologia, Porto Alegre: UFRGS, n. 10, 1993.

PIERUCCI, A. F.; PRANDI, R. A realidade social das religiões no Brasil. São Paulo: Hucitec, 1996.

PINTO, R. (Org.). Estudos afro-brasileiros. Rio de Janeiro: Ariel, 1935.

POLLAK-ELTZ, A. Umbanda en Venezuela. Caracas: Fondo Editorial Acta Cientifica, 1993.

PORDEUS Jr., I. Lisboa de caso com a umbanda. Revista USP, São Paulo, n. 31, p. 90-103, set./nov. 1996.

PRANDI, R. Os candomblés de São Paulo: a velha magia na metrópole nova. São Paulo: Hucitec: Edusp, 1991a.

PRANDI, R. Adarrum e empanadas: uma visita às religiões afro-brasileiras em Buenos Aires. Estudos Afro-Asiáticos, Rio de Janeiro, n. 21, p. 157-165, dez. 1991b.

PRANDI, R. Herdeiras do axé: sociologia das religiões afro-brasileiras. São Paulo: Hucitec, 1996a.

PRANDI, R. Religião e globalização. 1996b. Trabalho apresentado. VI Jornada sobre Alternativas Religiosas na América Latina, Porto Alegre, UFRGS, 6 a 8 de novembro de 1996.

PRANDI, R. A expansão da religião negra na sociedade branca: música popular brasileira e legitimação do candomblé. Trabalho apresentado. 1997a. XX International Congress of the Latin American Studies Association, LASA97, Guadalajara, México, 17 a 19 de abril de 1997.

PRANDI, R. Nas pegadas dos voduns. 1997b. Trabalho apresentado. $49^{\circ}$ Congresso Internacional de Americanistas, Simpósio Religião e Migração, Quito, 7 a 11 de julho de 1997. 
RODRIGUES, R. N. O animismo fetichista dos negros bahianos. 2. ed. Rio de Janeiro: Civilização Brasileira, 1935.

SANCHIS, P. As tramas sincréticas da historia. Revista Brasileira de Ciências Sociais, São Paulo, n. 28, p. 123-130, jun. 1995.

SANTOS, J. T. dos. O dono da terra: a presença do caboclo nos candomblés baianos. 1992. Tese (Mestrado em Antropologia)-Universidade de São Paulo, São Paulo, 1992.

SEGATO, R. L. Santos e daimones. Brasília: Editora UnB, 1995.

VALENTE, W. Sincretismo religioso afro-brasileiro. 3. ed. São Paulo: Nacional, 1977. 